\title{
Feasibility study of structural systems made from ceramics
}

\author{
Y Kaneko* and V C Li**
}

\begin{abstract}
The objective of this paper is to investigate the feasibility of making structural systems from ceramics. Segmental and composite systems are quantitatively studied, partial application of ceramics to traditional systems is considered, and the special application of a lunar base is studied. The quantitative and qualitative studies made indicate both advantages and disadvantages for ceramics in structural systems. However, the structural systems proposed may stimulate further studies to eliminate the disadvantages.
\end{abstract}

In a previous paper the authors' made a qualitative analysis of the applicability of advanced ceramics to construction based on a set of criteria; the results indicated both advantages and disadvantages in their use. To understand clearly and quantitively the performance of advanced ceramics for construction, it was suggested that structural systems in which the unique properties of advanced ceramics could be optimally utilized should be developed.

In this paper feasible structural systems for ceramics are investigated and the future utilization and mechanical performance of ceramics in construction are considered.

\section{Candldate materlals}

The mechanical properties of typical ceramics are given in Table $1^{2}$. Examples 1 and 2 represent high-performance ceramics: lithium aluminosilicate and silicon carbide, respectively. This table shows the considerable advantages of certain properties of ceramics over those of concrete and steel, indicating the potential of structural systems made from ceramics. However, the mechanical properties of monolithic ceramics are not adequate for use in structural systems because monolithics are brittle materials that usually fail abruptly without giving much warning in advance. Moreover, owing to their brittleness, the strength of ceramics is very sensitive to the flaw size in the material. Ceramic parts made from the same material may thus have very different strengths, making ceramics materials of low reliability. So ceramic toughness must be improved for structural systems.

There are several ways of improving ceramic toughness, but fibre reinforcement is by far the most effective means ${ }^{3}$. It has been shown that continuous-fibre reinforcements can greatly improve the reliability of ceramics because the sensitivity of first-cracking strength to flaw size is significantly reduced ${ }^{45}$ (first-cracking strength is the applied tensile stress at which an inherent flaw will propagate unstably across the whole section of the material). After first-cracking, the bridging of the crack by fibres allows the material to take further load. With increased loading, multiple cracks form, producing a pseudo-strain-hardening effect similar to that in metals $4,5,7$. This quasi-ductility provides a warning before final failure and also allows for stress redistribution to less severely loaded parts.

While continuous-fibre-reinforced ceramics have been shown to possess the desirable properties described, their use has been limited to parts of relatively simple geometric shape because it is very difficult and costly to construct continuous-fibre-reinforcing mesh for complex shapes. However, short fibres can be mixed with ceramic powders and formed into any shape by traditional powder compaction techniques.

* Department of Civil Engineering, MIT, Cambridge, MA 02139, USA. (On leave from Shimizu Corporation, Tokyo, Japan)

** Department of Civil Engineering, University of Michigan, Ann Arbor, MI 48109-2125, USA
Table 1 Mechanical properties

\begin{tabular}{|c|c|c|c|c|}
\hline & \multicolumn{2}{|c|}{ Ceramics $^{a}$} & \multirow{3}{*}{ Concrete } & \multirow{3}{*}{ Stee } \\
\hline & \multicolumn{2}{|c|}{ Example Example } & & \\
\hline & 1 & 2 & & \\
\hline $\begin{array}{l}\text { Density. } P \\
\left(\mathrm{Mg} \mathrm{m}^{-3}\right)\end{array}$ & \multicolumn{2}{|c|}{2.2} & 2.3 & 7.9 \\
\hline $\begin{array}{l}\text { Compressive } \\
\text { strength, } f_{c}(\mathrm{MPa})\end{array}$ & 1300 & 2000 & 40 & 220 \\
\hline \multicolumn{5}{|l|}{ Young's } \\
\hline $\begin{array}{l}\text { modulus } \\
E(\mathrm{GPa})\end{array}$ & 83 & 400 & 30 & 210 \\
\hline \multicolumn{5}{|l|}{$t_{\mathrm{c}}$} \\
\hline $\bar{\rho}$ & 590 & 910 & 17 & 28 \\
\hline \multicolumn{5}{|l|}{$E$} \\
\hline $\bar{\rho}$ & 38 & 180 & 13 & 27 \\
\hline
\end{tabular}

${ }^{a}$ Example 1 is typical of lithium aluminosilicate, glass-ceramics Example 2 is typical of silicon carbide, high-performance ceramics

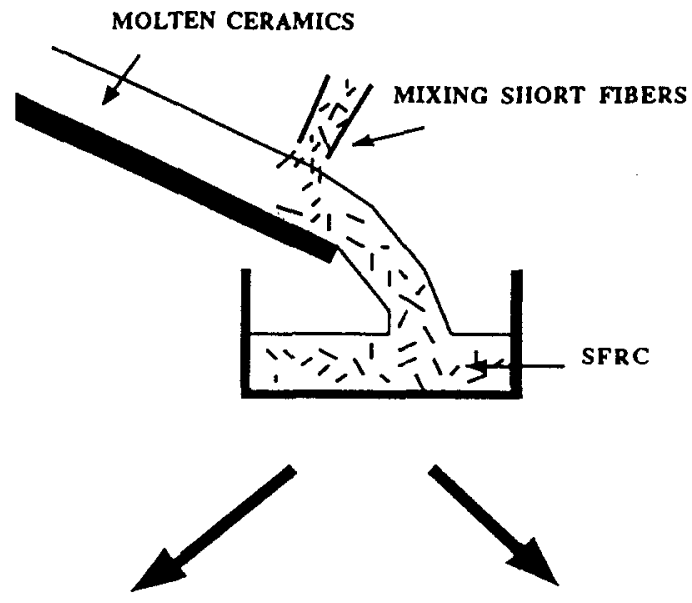

COMPOSITE 1

COMPOSITE 2
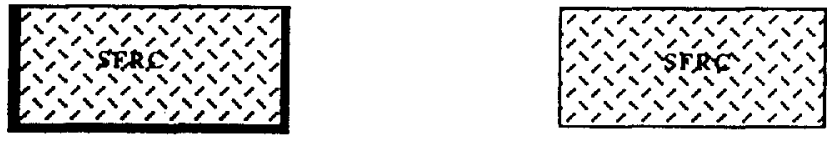

CERAMICS

SHORT FIBER

CERAMICS SHORT FIBER

Fig 1 Pouring technique 


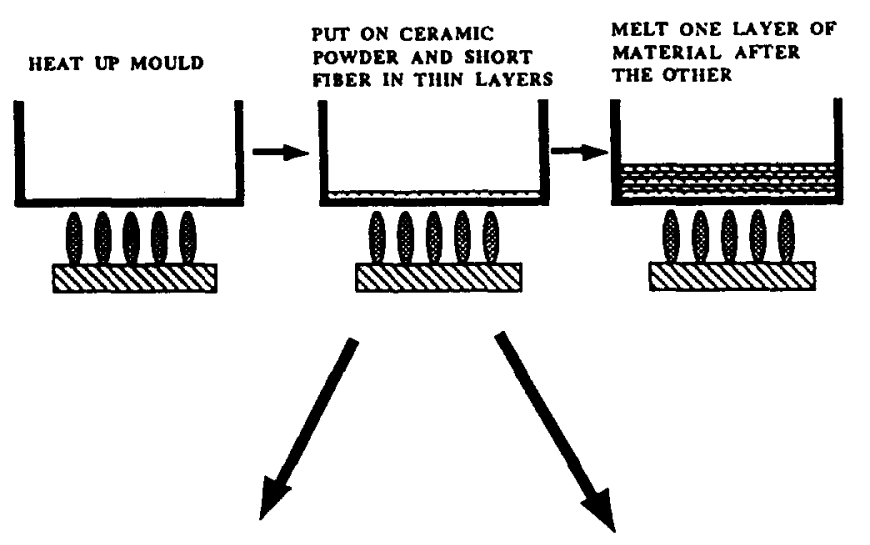

COMPOSITE 1

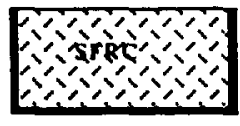

CERAMICS

SIIORT FIBER SIIORT

Fig 2 Casting technique

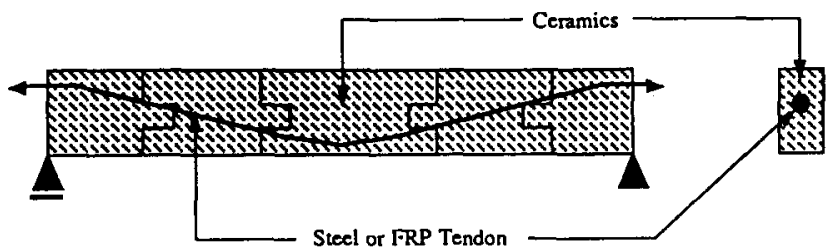

Elevation

Section

Fig 3 Segmental beam

While short-fibre-reinforced ceramics have a processing advantage over continuous-fibre-reinforced ceramics, an important issue to be resolved is whether the former possess similar desirable properties such as high reliability and multiple cracking.

The factors affecting the first-cracking strength of shortfibre-reinforced ceramics were studied to determine a criterion for high reliability and quasi-ductility ${ }^{8}$. The results showed that it is possible to tailor fibre, matrix and interface properties to produce a discontinuous fibre-reinforced ceramic composite that is notch-insensitive and possesses high reliability like certain continuous-fibre composites.

Based on such properties short-fibre-reinforced ceramics (SFRC) are considered for structural systems in this study.

Possible production processes include the pouring and casting techniques shown in Figs 1 and 2. In the former, ceramics are first heated up to the molten state and are then poured with short fibres into any shape of mould. This technique would enable production of both monolithic SFRC components, or composites with steel. In the latter, a mould is first heated up and ceramic powder and short fibres are put in layers. The final specimen is formed by melting one layer of material after another, which also enables production of both monolithic SFRC and composites with steel.

From the material properties and production processes discussed, it is apparent that SFRC structures could be realized as precast components, which could be used under compressive loading or moderate tensile loading. Based on these basic conditions, segmental applications, composite applications and finally partial and special applications are discussed.

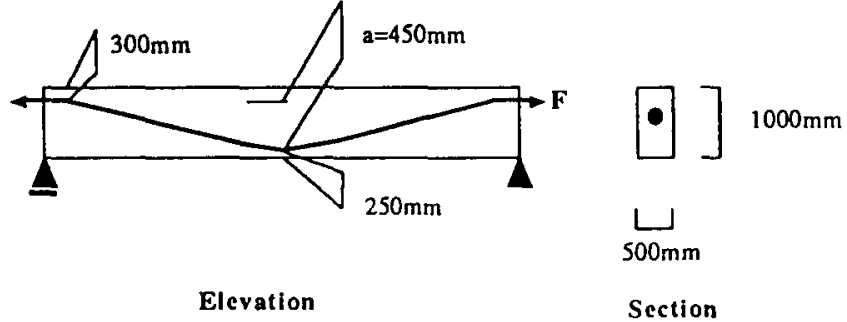

$q=50 \mathrm{KN} / \mathrm{m}$ (Dead Load), $20 \mathrm{KN} / \mathrm{m}$ (Live Load)

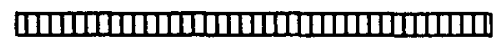

Loading Condition

\section{Fig 4 Geometric and loading configuration}

\section{Segmental applications}

\section{Segmental beam}

The elevation and section of a segmental beam are shown in Fig 3. The whole structure could be made of ceramics except for the steel or FRP (fibre-reinforced plastic) tendon. Each block of ceramics could be precast as discussed earlier. The blocks could be assembled into a beam structure by joining the components together through shear keys and stabilized through the induced compressive stresses produced by the tendon. The aim of this application is to make a long-span beam with high durability. To assess this application quantitatively, a comparison with a prestressed concrete beam was made as follows.

The model is shown in Fig 4. Assuming the density of ceramics to be the same as that of concrete, the same structural dimensions are used in the analysis. The analytical assumptions are as follows.

- There is no reinforcement except a steel or FRP tendon, which can be used to cancel the effect of a vertical load. The materials are not loaded beyond the elastic range and hence can be considered as elastic. It is also assumed that there is no tensile stress on any section.

- Although there is a minimum allowable spacing between tendons in the section, it is neglected in order that simple comparisons can be made between concrete and ceramics.

- Material strength can be used as the allowable maximum stress.

- The 'load balancing method' can be adopted. An upward uniform load of the tendon can balance out the dead load of beam. In this case, the live load cannot be cancelled by the upward uniform load of the tendon because the live load cannot always exist on the structure.

- The maximum deflection is restricted to less than $L / 300$, where $L$ is the span.

With these assumptions, the maximum span of the beam with no tensile stress on its section was calculated (see Appendix 1). Results for ceramic beams and concrete beams are shown in Fig 5. Although the effect of ceramics is apparent, the results obtained are much lower than had been expected, especially for glass-ceramics. This is because the maximum span is governed by beam deflection. Although the compressive strength of ceramics is $30 \sim 50$ times that of concrete, the Youngs modulus of the former is only about $3 \sim 10$ times the latter. An optimum design is one where the maximum stress at maximum allowable deflection is just under the allowable stress. The maximum stress on the ceramics is much lower than the material strength, but the maximum stress on the concrete section is almost the same as the material strength, so the concrete beam is closer to 


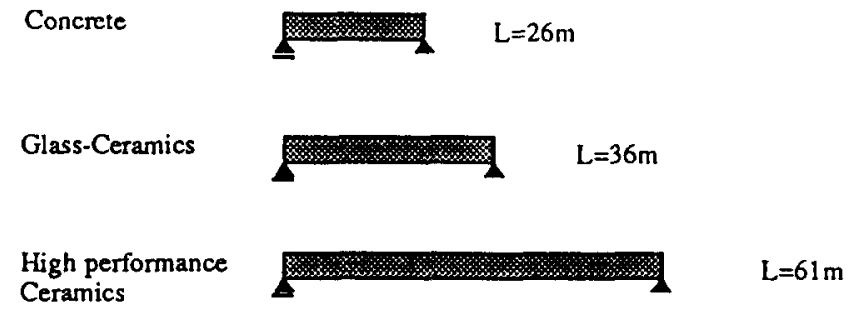

Fig 5 Maximum span

achieving an optimum design. However, in some applications, some requirements (such as maximum span) preclude an optimum design and a ceramic beam could be used.

It is interesting to find the optimum design condition mentioned in terms of material properties. This design condition in our analysis could be expressed by the following equation (see Appendix 1):

$$
\frac{\sigma_{c}}{E} \approx \sqrt{\frac{1}{3900} \times \frac{d}{a b} \times \frac{q_{D L}}{\sigma_{c}}}
$$

where $\sigma_{c}$ is the compressive strength, $E$ is Young's modulus, $d$ and $b$ are the depth and width of the cross section, $a$ is the rise of the tendon and $q_{\mathrm{DL}}$ is dead load. By using this equation, the optimum ratio of compressive strength to Young's modulus can be calculated as follows:

$$
\begin{array}{ll}
\text { glass-ceramic beam } & \frac{\sigma_{\mathrm{c}}}{E} \approx \frac{1}{4800} \\
\text { high-performance ceramic beam } & \frac{\sigma_{\mathrm{c}}}{E} \approx \frac{1}{5900} \\
\text { concrete beam } & \frac{\sigma_{\mathrm{c}}}{E} \approx \frac{1}{850}
\end{array}
$$

Also, the same ratio can be calculated from the actual material properties (see Table 1):

$$
\begin{array}{ll}
\text { glass-ceramic beam } & \frac{\sigma_{\mathrm{c}}}{E} \approx \frac{1}{60} \\
\text { high-performance ceramic beam } & \frac{\sigma_{\mathrm{c}}}{E} \approx \frac{1}{200} \\
\text { concrete beam } & \frac{\sigma_{\mathrm{c}}}{E} \approx \frac{1}{750}
\end{array}
$$

Comparison of both values for each material shows that concrete is closer to the optimum ratio than ceramics. This ratio may become a useful index for ceramic material design.

\section{Segmental shell}

The shapes of the shell and the components are shown in Fig 6. These components are made from ceramics only. Each component can be precast by pouring the molten ceramics into moulds of the appropriate shape. They can be assembled into shell structures by joining the components together through shear keys. By applying prestressing (eg on the vertex of the shell roof: tension column), this structural system could become stable because of the induced compressive stresses. Thus, the ceramic shell is under compressive membrane stress, but there is still tensile stress due to local bending moment.

Several possible methods for reducing local bending are:

- casting some members between the tension column and the ceramic shell to break up the concentrated load;

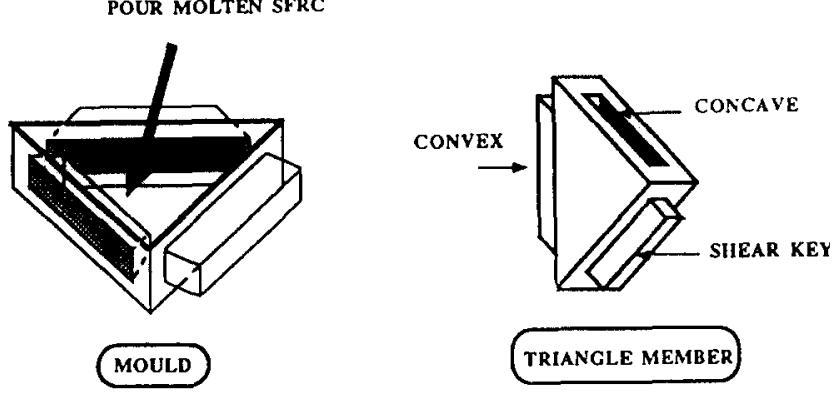

Prestressing

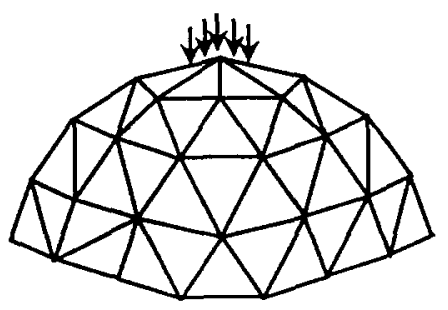

SHELL ROOF

Fig 6 Segmental shell

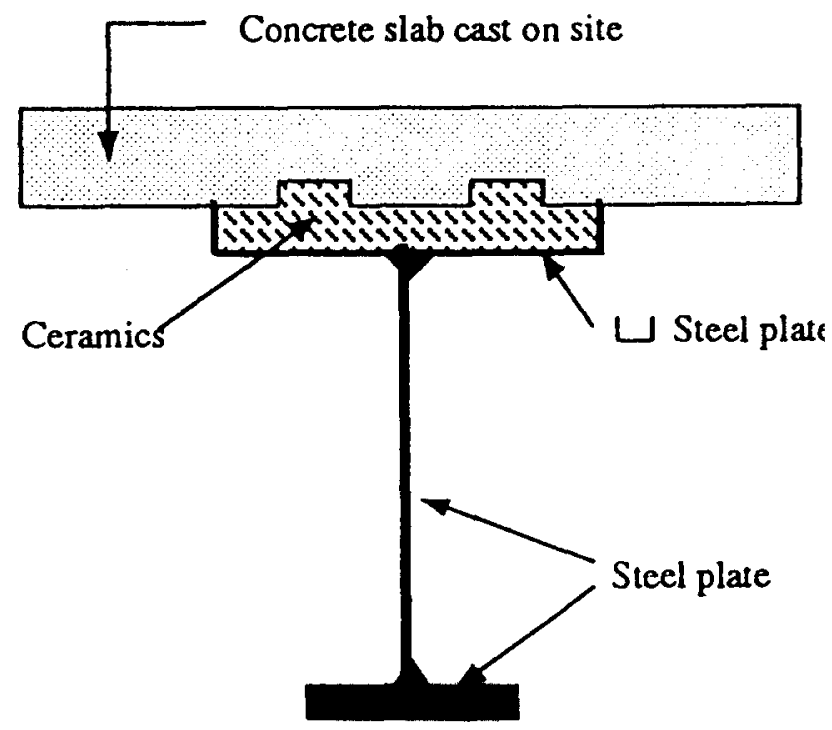

Fig 7 Composite beam

- changing the curvature between the top part and the bottom part of the ceramic shell;

- changing the shell thickness between the top part and bottom part of the ceramic shell.

\section{Compodte applications}

\section{Composite beam}

The section of a composite beam is shown in Fig 7. Ceramics could be used in the upper flange of the steel I-beam. The beam can be precast by pouring the molten ceramics into a thin steel channel at the upper flange to make a stiff and lightwoight composite beam to be used in steel structures. To assess the application quantitatively, the following comparison with a pure steel beam was made.

For comparison, it is necessary to analyse a composite beam with the same weight as a pure steel beam (heavy weight can be deleterious to steel structures). To obtain the flexural stiffness $E /$ of the composite beam, the upper flange 

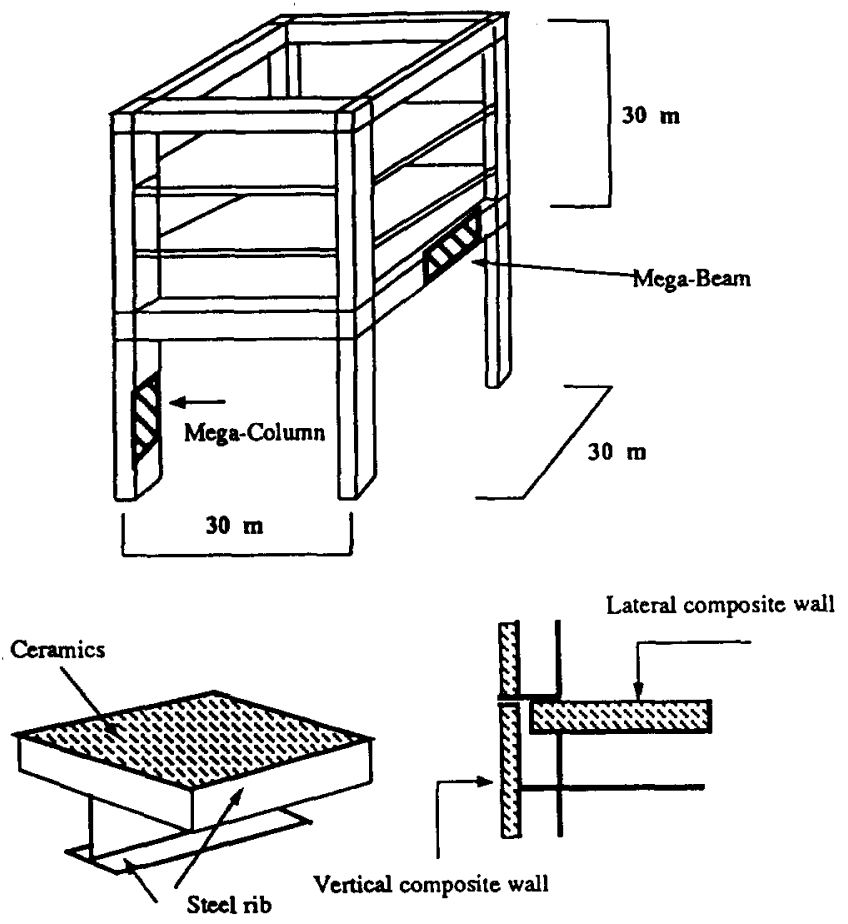

One unit of composite wall

Joint of of each unit

\section{Fig 8 Composite wall in mega structure}

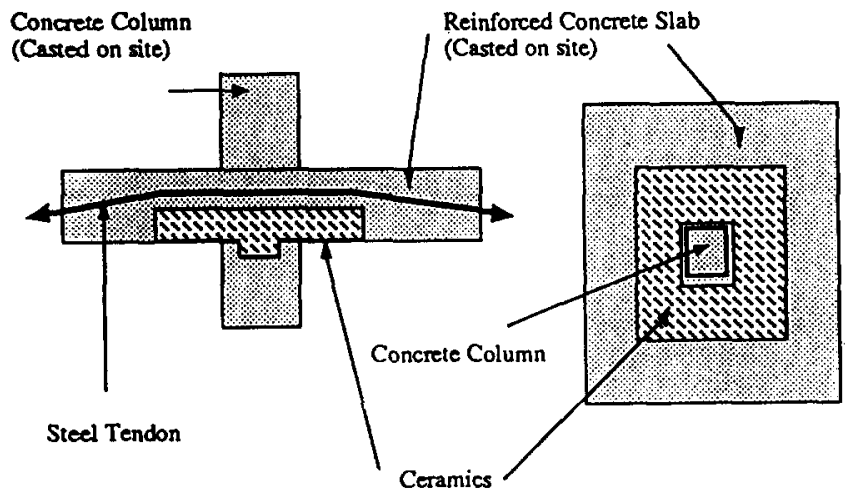

Elevation

Section

Fig 9 Flat plate reinforcement

of ceramics was replaced by an equivalent section of steel (see Appendix 2). In the calculation of ultimate strength $M u$, it was assumed that the steel section had sufficient ductility to form a plastic hinge. Then the neutral axis was assumed to be at the interface between the ceramics and the steel. Tension force in the whole steel area was equivalent to compressive force in the ceramics area. El and $M u$ of the composite beam are compared with values for a steel beam. The results for a glass-ceramics composite beam (composite 1) and high-performance ceramics composite beam (composite 2) are as follows:

$$
\begin{array}{rlrl}
\frac{E I_{\text {composite 1 }}}{E I_{\text {steel }}}=1.1 & \frac{E I_{\text {composite 2 }}}{E I_{\text {steol }}}=1.8 \\
\frac{M u_{\text {composite 1 }}}{M u_{\text {steel }}}=1.2 & \frac{M u_{\text {composite 2 }}}{M u_{\text {steol }}} & =1.2
\end{array}
$$

Although the effect of ceramics on El is apparent, the results obtained are much lower than had been expected, particularly for glass-ceramics. The values of $M u$ are also lower than expected, particularly for high-performance ceramics. This is because the maximum compressive stress of ceramics is much lower than the material strength in both composite beams, while the steel yields completely. In other words, the flexural strength of composite beams is limited by the strength of steel, which is much lower than for ceramics.

\section{Composite wall}

It is possible to expand the composite beam application to a composite-wall application. This composite wall may be used in a 'Mega' structure (Fig 8). Mega-columns and megabeams have box-shape sections with flanges composed of composite wall. The manufacturing process of the composite wall is the same as that of the previous composite beam. Mega-columns and mega-beams may be assembled by joining each unit of composite wall through steel ribs, which could also be used to resist local bending.

\section{Partial applications}

\section{Flat-plate reinforcement}

So far, several applications on a whole structure or a whole member have been discussed. In this section, the partial application of SFRC in conventional structural systems is discussed.

SFRC are used at a flat plate shown in Fig 9. Ceramics can be placed at the bottom of the slab to make a high-shearresistant capital in a flat-plate structure to resist loading from the column. Under gravity load, a compressive-shear-stress state exists. Owing to the high ratio of compressive strength to density, ceramics are very effective materials for this application. However, for seismic loading, a tensile-shearstress state can also exist at the bottom of the slab, so tensile stresses must be considered in this application.

\section{Beam-column joint reinforcement}

Next the partial application of SFRC at the joint in a frame structure is considered. The elevation and the perspective are shown in Fig 10. Cubic ceramics precast with steel reinforcement may be set at the joint to make a rigid joint. Little attention has been given to the design of joints in reinforced concrete structures although joints are often the weakest links in a structural system. Also, the strength of the joints should not normally govern the strength of structures. In particular, with the recent increase in the use of highstrength reinforcement and concrete, higher stiffnesses and strengths are required in beam-column joints. In the beamcolumn joint, a compressive strut is formed to balance the bending moment; ceramics can be effective in this part. However, since tensile stresses also occur at the joint, they must be considered in this application.

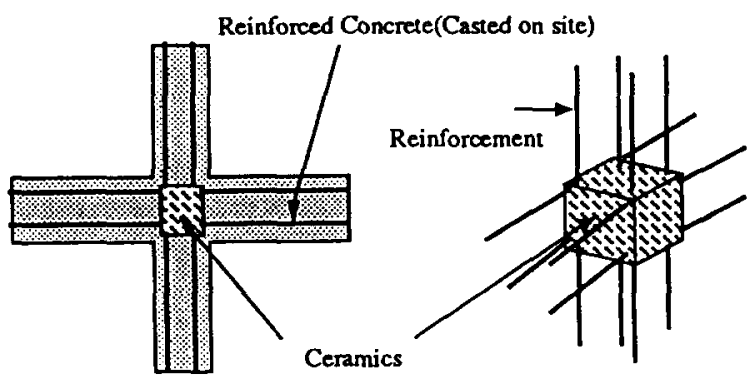

Elevation

(4) Fig 10 Ceramics on beam-column-joint 


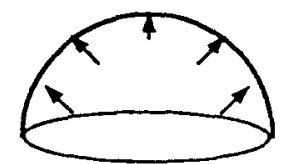

Ifemi-Sphere structure

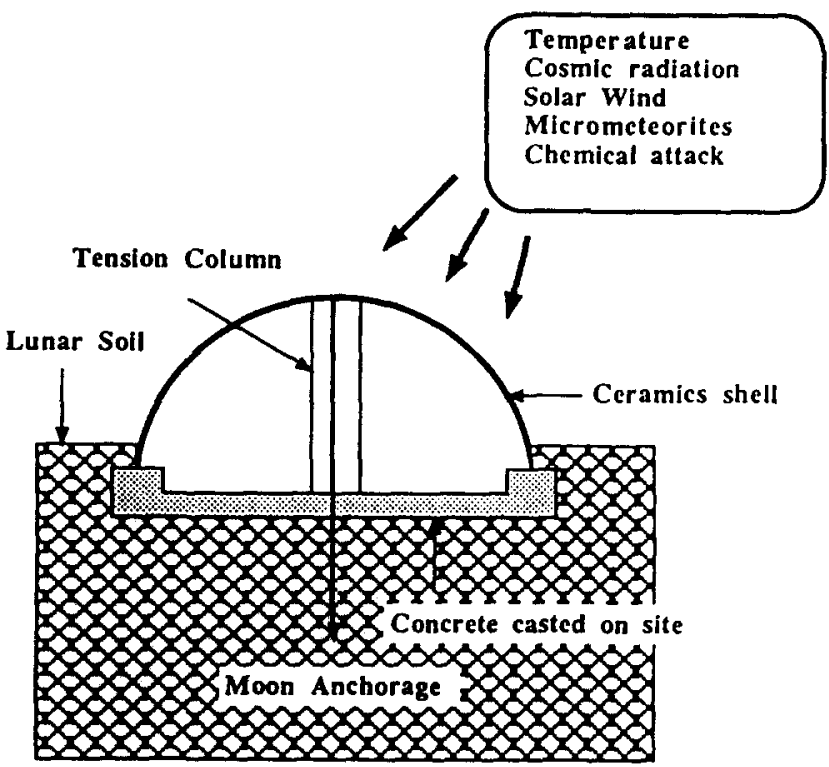

Fig 11 Lunar base

\section{Special appllcations}

So far, structural systems making use of the mechanical properties of advanced ceramics under ordinary environments have been considered. However, other properties of advanced ceramics such as the thermal and chemical properties, are also outstanding, and the lunar base is an example of an application where they can be used to advantage.

Many feasibility studies for a lunar base have been made by space researchers and structural engineers. ${ }^{9}$ A lunar bese would experience very large temperature variations, from $137^{\circ} \mathrm{C}\left(279^{\circ} \mathrm{F}\right)$ during the day to $-190^{\circ} \mathrm{C}\left(-310^{\circ} \mathrm{F}\right)$ at the end of the lunar night, as well as being subjected to cosmic radiation and solar wind. In the absence of a protective atmosphere, bombardment by micrometeorites could also cause problems. Under the high vacuum and anhydrous conditions, the chemical stability and strength of some materials would be significantly affected. The durability of materials in the demanding lunar environment is a major design consideration.
The primary loading affecting the geometry and dimensions of the structure is the internal pressure of the 'shirt sleeve' atmosphere desirable within the enclosed biosphere. For most functional areas, this pressure could be about $10 \mathrm{psi}(70 \mathrm{kPa})$. Loading also arises from the force of gravity on the massive shielding, with about 6 to $9 \mathrm{ft}(2$ to $3 \mathrm{~m}$ ) of regolith(lunar soil) used to protect the structure from thermal, chemical and mechanical problems of the lunar environment. Ceramics appear to be a possible material to satisfy the requirements for the lunar base.

The elevation of a lunar base is shown in Fig 11. The shape is hemispherical and the shell is made from small ceramic components, which were previously shown in Fig 6. A tension column anchored to the moon soil supports the internal pressure in the ceramic shell and induces compressive stresses to make this structure stable; local tensile stresses discussed in segmental shell applications must also be considered.

\section{Conclusions}

In this paper, several types of structural system in which the properties of ceramics or SFRC might be optimally utilised have been studied. Both the advantages and disadvantages of making such structural systems have been indicated and it is believed further studies could reduce the disadvantages.

More detailed analyses of the mechanical behaviour of structural systems are required. Fracture behaviour will be considered in a future paper.

\section{Peferences}

1 Kaneko, Y and LI, V C The use of advanced materials in the construction industry - Applicability of ceramics to construction Serviceability and Durability of Construction Materials (Ed. Bruce A Suprenant) Vol 1 of Proc First Eng Cong, Denver, USA (13-15 August 1990) p 795-803

2 LI, V C and Loung, CK Y Ceramics for Construction Construction \& Building Materials 2 (2) (1988) p 59-68

3 Evans, A G. The new high toughness ceramics Rep 1987-1 Univ of California, Santa Barbara, USA (1987)

4 Marshall D B, Cox, B N and Evone, A G The Mechanics of matrix cracking in brittle-matrix fiber composites Acta Metall 33 (11) (1985) p 2013-21

5 Marshall, D B and Evans, A G Failure mechanisms in ceramicfiber/ceramic-matrix composites J Am Ceram Soc 68 (5) (1985) p 255-231

6 Marshall, D B and Cox, B N Tensile fracture of brittle matrix composites: Influence of fiber strength Acta Metall 35 (11) (1987) p 2607-2619

7 Aveston, J, Cooper, G A and Kolly, A Single and multiple fracture NPL Con Proc Properties of Fiber Composites IPC Sci \& Technol Publishers, (1971) p 15-26

8 Loung, C K and $L i, V$ C First-cracking strength of short-fiber reinforced ceramics Ceram Eng Sci Proc, 9/10, (1989) p 1164-1178

9 American Soclety of Clvil Engineers Engineering, Construction and Operations in Space (1988)

where $q_{u}$ is the live load $\left(\mathrm{Nm}^{-1}\right)$. Tensile stress at the bottom fibre of a section due to a live load is

$$
\sigma_{\mathrm{LL}}=\frac{M_{\mathrm{LL}}}{Z}
$$

where $Z$ is a geometric moment of area.

Substituting Equations (A.1) and (A.2) into (A.3) gives

$$
\sigma_{\mathrm{LL}}=\frac{6 a \sigma_{\mathrm{p}} q_{\mathrm{LL}}}{d q_{\mathrm{DL}}}
$$

where $d$ is the depth of the beam section. 
To obtain zero stress at the bottom fibre of a section, $\sigma_{p}$ is made equal to $\sigma_{\mathrm{LL}}$. Thus

$$
q_{\mathrm{LL}}=\frac{d q_{\mathrm{DL}}}{6 a}
$$

This is the condition in which there is a compressive stress $\sigma_{\mathrm{p}}$ at any section for $q_{\mathrm{DL}}$, and there is a zero stress at the bottom fibre of a section and a compressive stress $2 \sigma_{p}\left(=\sigma_{\mathrm{p}}+\sigma_{\mathrm{LL}}\right)$ at the top fibre of a section for $q_{\mathrm{DL}}+q_{\mathrm{LL}}$. To prevent fracture by crushing, the following condition at the top fibre of a section must be satisfied.

$$
2 \sigma_{\mathrm{p}} \leqslant \sigma_{\mathrm{c}}
$$

where $\sigma_{\mathrm{c}}$ is compressive strength.

To restrict a large deflection, there is the condition:

$$
\delta=\frac{5 q L L^{4}}{384 E I} \leqslant \frac{L}{300}
$$

where $\delta$ is the vertical deflection of the beam, $E$ is Young's modulus and $I$ is the moment of second order.

Substituting Equation (A.1) into (A.7), gives

$$
\sigma_{\mathrm{p}} \leqslant\left(\frac{d q_{\mathrm{pL}} E^{2}}{31250 \mathrm{ba}}\right)^{1 / 3}
$$

where $b$ is a width of the beam section.

Equations (A.6) and (A.B) are the conditions that can cover the design conditions of maximum allowable stress and deflection. By using those equations maximum $\sigma_{p}$ can be obtained. Substituting the $\sigma_{p}$ obtained into Equation (A.1), the maximum span $L$ can be obtained. Existing maximum compressive stresses at the top fibre of ceramics and concrete are as follows (the values of $q_{\mathrm{DL}}$ and $q_{\mathrm{LL}}$ in Fig 4 are used):

concrete

glass-ceramics

$37 \mathrm{Mpa}<40 \mathrm{Mpa}\left(=\sigma_{c}\right)$

$73 \mathrm{Mpa}<1300 \mathrm{Mpa}\left(=\sigma_{\mathrm{c}}\right)$

high-performance ceramics $209 \mathrm{Mpa}<2000 \mathrm{Mpa}\left(=\sigma_{\mathrm{c}}\right)$

An optimum design is one with the maximum stress at maximum allowable deflection just under the allowable stress. This optimum design condition could be expressed by

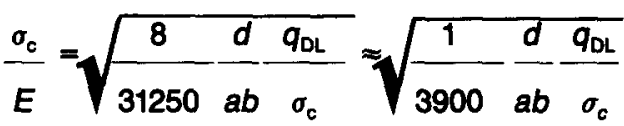

\begin{abstract}
Appendix 2: Flexural stiffness and strength in composite beam

To calculate the flexural stiffness in a composite beam, the method of equivalent section was adopted. The upper flange of the composite beam may work as an axial member for compressive force. By equating the axial stiffness of the upper flange in the composite beam to that in the equivalent section of steel $(\mathrm{H}-800 \times 300 \times 16 \times 32)$, the equivalent steel section with flexural stiffness almost equal to that of the composite section can be obtained. The flexural stiffness of this equivalent section can be calculated by usual methods. The results are as follows:
\end{abstract}

$$
\begin{aligned}
& \text { glass-ceramics (composite 1) } \quad I=3.61 \times 10^{9} \mathrm{~mm}^{4} \\
& \text { high-performance ceramics (composite } \\
& \begin{array}{ll}
\text { 2) } & I=5.93 \times 10^{9} \mathrm{~mm}^{4} \\
\text { pure steel section }(\mathrm{H}-800 \times 300 \times 16 \times 32) & I=3.36 \times 10^{9} \mathrm{~mm}^{4}
\end{array}
\end{aligned}
$$
Since the compressive strength of ceramics is much higher than that of ste日l, the neutral axis at an actual ultimate stress distribution is on the ceramic section (Fig 12), resulting in the tensile stress on the ceramic section. This may not be a desirable situation, so, as the flexural strength of the composite beam, the critical strength in which the neutral axis is at the interface between ceramics and steel was used to obtain no tensile stress on the ceramic section. This critical strength may be almost the same as that of actual ultimate flexural strength and could be conservative. As a result, the

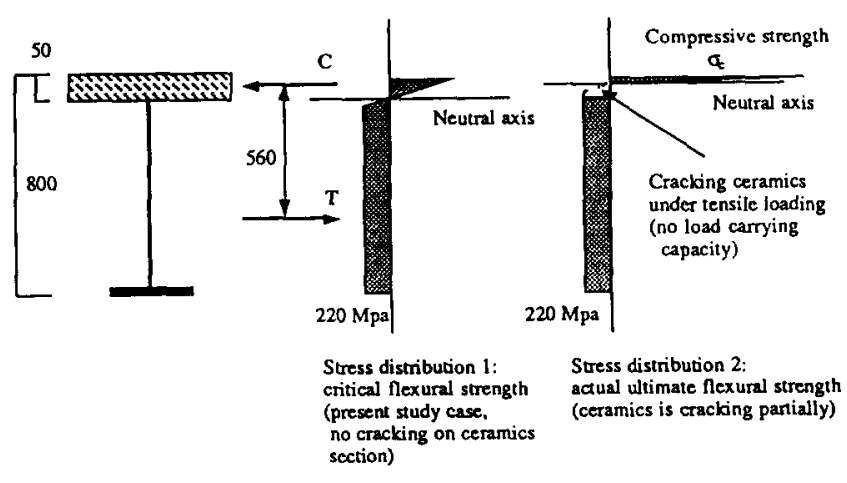

Fig 12 Flexural strength of the composite beam

flexural strength when using high-performance ceramics is the same as that for glass-ceramics. The flexural strength of steel can be calculated such that $M u=\sigma_{T} Z_{p}$, where $M u$ is a plastic moment, $\sigma_{T}$ is a tensile strength and $Z_{p}$ is a plastic moment of first order. The results are
Steel
$M u=9.54 \times 220=2.1 \mathrm{MN} \mathrm{m}$
Composite $1 \stackrel{M u}{M u}=2.58 \mathrm{MN} \mathrm{m}$
Composite $2 \mathrm{Mu}=2.58 \mathrm{MN} \mathrm{m}$ 